\title{
The Instrumented Indentation Study of HVOF-Sprayed Hardmetal Coatings
}

\author{
Šárka Houdková, Olga Bláhová, František Zahálka, and Michaela Kašparová
}

(Submitted April 27, 2011; in revised form June 21, 2011)

\begin{abstract}
Elastic-plastic properties, namely, hardness and Young's modulus, of four HVOF-sprayed hardmetal coatings were measured by instrumented indentation using Oliver-Pharr method Nanoindenter XP MTS with a continuous stiffness measurement (CSM) module. The results show that with sufficient number of CSM measurements, one can distinguish between indents made in the hard particles and indents made in the binder material. This can be accomplished by analyzing the plots of hardness and Young's modulus versus load (or versus indentation depth). Further development of the dependence curves enables the load (or indentation depth) to be set to correspond to the point of transition from a single structure component to the composite material and to determine the properties of both. Comparison of results of CSM measurement with the results of single indentation measurement at a defined load reveals a new perspective on the origin of the indentation size effect in hardmetal coatings. The measurements show that the increase in both the hardness and Young's modulus with decreasing load is caused mainly by the predominant influence of hard particles in the coatings.
\end{abstract}

Keywords coating, hardmetal, hardness, HVOF, mechanical properties, nanoindentation, thermal spraying, Young's modulus

\section{Introduction}

For evaluation of mechanical properties of thermally sprayed coatings, it is necessary to take into consideration their unique, heterogeneous lamellar microstructure. In addition to hardness, Young's modulus, fracture toughness, the coatings' porosity, cohesive strength, the content of oxides, and other microstructural defects also play their role (Ref 1,2). While the mechanisms of formation of such coatings have been investigated in depth, detailed information on mechanical properties still remains difficult to obtain because of coatings' heterogeneity. Macro-scale methods, such as three- (Ref 1,3$)$ or four-point bending test (Ref 4-6), tensile test (Ref 5) or surface hardness, and microhardness measurement do not capture all the effects of the strongly heterogeneous structure containing features resulting from the spraying process. In the case of sprayed hardmetals, the coatings' microstructure is even more complicated, containing numerous hard particles in soft binding matrix in each individual splat.

Šárka Houdková and Olga Bláhová, New Technologies Research Centre, University of West Bohemia, Univerzitní 22, 30614 Plzeň, Czech Republic; and František Zahálka and Michaela Kašparová, VZÚ Plzeň s.r.o., Tylova 46, 31600 Plzeň, Czech Republic. Contact e-mails: houdkov@ntc.zcu.cz, blahova@ntc. zcu.cz, zahalka@vzuplzen.cza and kasparova@vzuplzen.cz.

Indentation methods, particularly the instrumented indentation, enable hardness, viscoelastic properties, and Young's modulus to be determined within very small material volumes. They also have the potential to capture not only intrinsic material characteristics within a single splat but also the properties of a single hard particle and the binder material. Knowledge of basic mechanical properties is important for predicting the coating's behavior under different types of loading. These properties include hardness and Young's modulus of each structure component, as well as their $E / H$ ratio. They characterize the elastic-plastic behavior of the materials. It is also necessary for determining the indentation fracture toughness (Ref 7). Information obtained from indentation tests can be crucial for predicting the abrasive wear behavior of the coatings when sharp-edged abrasive media attack the coating surface in a manner very similar to indentation.

Indentation methods are commonly used for bulk materials, thin coatings, and other types of materials. Their related phenomena, such as the indentation size effect, are well described (Ref 8-16). However, this does not quite apply to thermally sprayed coatings. Up to now, the mechanical properties of hardmetal coatings have been evaluated mostly in terms of the composite scale range. Traditionally, indentation tests are used for measuring surface hardness of thermally sprayed coatings (HR15N) and their microhardness (HV0.3 or HV0.1) on the coating's cross section. The instrumented indentation was used several times for evaluation of structure component properties (Ref 17) and for evaluation of properties in the range of one splat (Ref 18-29). Only a few articles (Ref $21,27,29,30)$ have reported the application of continuous stiffness measurement (CSM) method for characterizing hardness and Young's modulus across a wide range of the microstructural scale.

In the present study, the HVOF-sprayed hardmetal coatings were measured by instrumented indentation. 
Continuous stiffness measurement (CSM) up to $10 \mathrm{~N}$ was used, as it is capable of determining hardness $\left(H_{\mathrm{IT}}\right)$ and Young's elastic modulus $\left(E_{\mathrm{IT}}\right)$ using the displacement into surface. More than 50 indentations were made in each material in randomly selected areas regardless of the coating's microstructure. The results show that with sufficient number of CSM measurements, the difference between indents made in the hard particles and those in the binder material can be recognized. Despite this, most measurement data characterize combined elastic-plastic properties of both.

\section{Experimental}

The coatings examined in this study were sprayed onto flat grit-blasted surfaces of samples using the Praxair JP 5000 HVOF-spraying system at the institute VZÚ Plzeň s.r.o. The spraying parameters are summarized in Table 1.

While the WC-17\%Co, WC- $12 \% \mathrm{Co}$, WC- $20 \% \mathrm{CrC}-$ $7 \% \mathrm{Ni}$, and $\mathrm{Cr}_{3} \mathrm{C}_{2}-25 \% \mathrm{NiCr}$ coating materials are commercially available, the (Ti,Mo)(C,N)-37\%NiCo powder with core-rim-structured hard phases was an experimental powder, first tested by Berger et al. (Ref 31). Thickness of coatings varied from 300 to $500 \mu \mathrm{m}$. The size ranges of hard phases were different in each coating. The size of WC carbides varies between 1 and $5 \mu \mathrm{m}$ for $\mathrm{WC}-12 \% \mathrm{Co}$ and WC- $17 \% \mathrm{Co}$; the size of $\mathrm{Cr}_{3} \mathrm{C}_{2}$ carbides ranged between 5-10 $\mu \mathrm{m}$ for $\mathrm{Cr}_{3} \mathrm{C}_{2}-\mathrm{NiCr}$. Hard particles in the WC-CrC-Ni coating are mostly smaller than $1 \mu \mathrm{m}$. However, it also contains a minority of carbides with the size approaching $2 \mu \mathrm{m}$. In the coating, the WC carbides are combined with $(\mathrm{W}, \mathrm{Cr})_{2} \mathrm{C}$ carbides with varying content of $\mathrm{Cr}$ ( Ref 32, 33). In the case of carbides and nitrides in the ( $(\mathrm{Ti}, \mathrm{Mo}) \mathrm{C}, \mathrm{N})-$ NiCo coatings, the size is rather difficult to estimate because of the special core-rim structure of hard phases, but it could be evaluated as smaller than three micrometers. Moreover, the hard phases do not have distinct boundaries: their composition changes from the rim to the center (Ref 34). An SEM micrograph of measured coatings is shown in Fig. 1. Detailed characterization of their microstructure can be found elsewhere (Ref 31, 32, 34, 35); their basic mechanical properties are summarized in Table 2 .

The indentation measurement was performed using the MTS NanoIndenter XP with a CSM module (Continuous Stiffness Mode). CSM testing is based on oscillating load withamplitude of several orders of magnitude smaller than the nominal load. This oscillating load is superposed onto the primary nominal load. Indentation is performed automatically, and the position for indentation is chosen with high precision. It is possible to pre-program a set of experiments. The output of measurement is generally an indentation curve (displacement into surface as a function of the load on the sample). The values of instrumented hardness $\left(H_{\mathrm{IT}}\right)$ and instrumented Young's modulus $\left(E_{\mathrm{IT}}\right)$ were calculated using the Oliver-Pharr model (Ref 36). (Young's modulus $\left(E_{\mathrm{i}}\right)$ and Poisson's ratio $\left(v_{\mathrm{i}}\right)$ of the Vickers indenter used were $1.141 \mathrm{GPa}$ and 0.07 , respectively.) The CSM module allows hardness to be measured continuously as a function of indenter depth of penetration into the testing material.

For each coating, 50 randomly distributed measurements were taken on the coating's polished cross section, after the samples had been embedded in resin. The indentation procedure consists of a loading period with the maximum load of $10 \mathrm{~N}$, followed by dwell time (30 s) and unloading. The measured data-dependences of hardness $H_{\mathrm{IT}}$ on the displacement into surface-was analyzed and ranked into three groups that represent the measurement of hard particles, soft matrix, and the mixture of both.

Besides the CSM measurements, 10 independent measurements with defined loads were made at $20 \mathrm{mN}, 200 \mathrm{mN}$, $1 \mathrm{~N}, 2 \mathrm{~N}, 5 \mathrm{~N}$, and $10 \mathrm{~N}$. The same Oliver-Pharr model (Ref 36) was employed to calculate the $H_{\mathrm{IT}}$ and $E_{\mathrm{IT}}$ values.

\section{Results and Discussion}

To distinguish between data for hard phases, the matrix, and the mixture of both, sufficient number of CSM measurements is necessary. The shape of the hardnessload dependence is the guideline for the classification: the hardness-load dependence obtained from the measurement of pure hard phase reached, at its highest point, the value of $H_{\mathrm{IT}}$, corresponding to the $H_{\mathrm{IT}}$ of this hard particle. With increasing depth of indentation, the current value of $H_{\mathrm{IT}}$ decreased to the level of the composite $H_{\mathrm{IT}}$.

On the other hand, the ideal hardness-load dependence curve from measurement of the matrix does not have its highest point at the beginning; the curve keeps rising to the composite values.

Most measurements have to be classified as combination of both components: the hard phase, influenced by surrounding matrix-or the matrix influenced by hard phases embedded in its neighborhood. The shapes of the hardness-load dependence curves resemble the depen-

Table 1 Spraying parameters

\begin{tabular}{|c|c|c|c|c|}
\hline Coating & Eq. ratio & Carrier gas & Barrel length, mm & Spraying distance, $\mathrm{mm}$ \\
\hline WC- $12 \%$ Co & 0.8 & Argon & 150 & 380 \\
\hline WC-17\% Co & 0.8 & Argon & 150 & 380 \\
\hline WC- $20 \% \mathrm{CrC}-7 \% \mathrm{Ni}$ & 0.8 & Argon & 100 & 380 \\
\hline $\mathrm{Cr}_{3} \mathrm{C}_{2}-25 \% \mathrm{NiCr}$ & 0.8 & Argon & 150 & 360 \\
\hline$(\mathrm{Ti}, \mathrm{Mo})(\mathrm{C}, \mathrm{N})-37 \% \mathrm{NiCo}$ & 1 & Argon & 150 & 380 \\
\hline
\end{tabular}



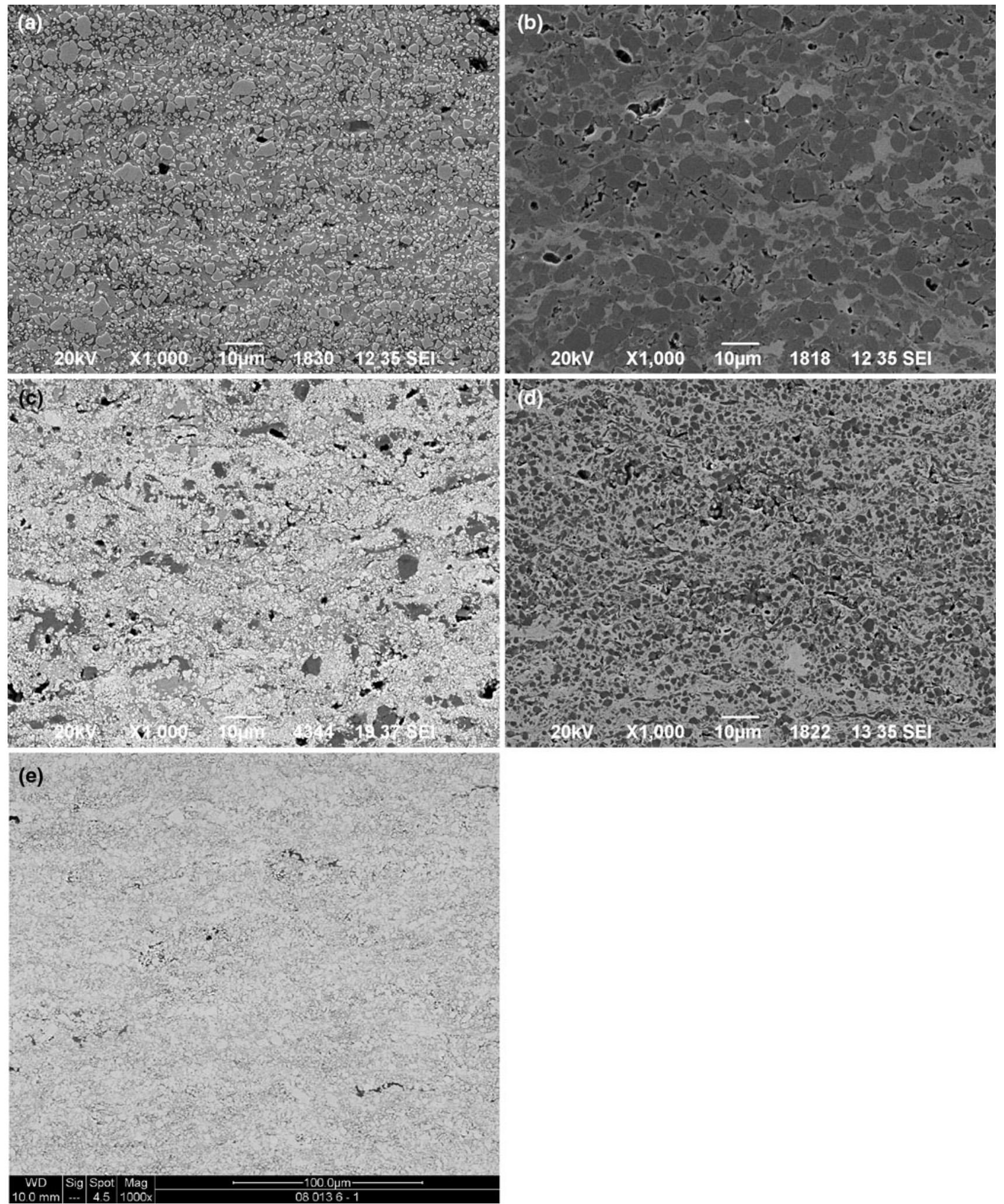

Fig. 1 Microstructure of (a) WC-17\%Co, (b) $\mathrm{Cr}_{3} \mathrm{C}_{2}-25 \% \mathrm{NiCr}$, (c) WC-CrC-7\% Ni, (d) (Ti,Mo)(C,N)-37\%NiCo, and (e) WC-12\%Co

dence curves for hard particle measurement, but the highest measured $H_{\mathrm{IT}}$ value does not reach the expected $H_{\text {IT }}$ value of pure hard particles.
The measured dependences of $H_{\mathrm{IT}}$ and $E_{\mathrm{IT}}$ on the displacement into surface are shown in graphs in Fig. 2-6. The dotted curves stand for an average of the measurements 
Table 2 Coatings properties

\begin{tabular}{lccc} 
Coating & Thickness, $\boldsymbol{\mu m}$ & HV0.3, GPa & HR15N \\
\hline WC-12\%Co & $345 \pm 23$ & $8.86 \pm 1.37$ & $90.0 \pm 1.9$ \\
WC-17\%Co & $442 \pm 10$ & $13.09 \pm 1.53$ & $90.0 \pm 0.3$ \\
WC-20\% CrC-7\% Ni & $485 \pm 12$ & $8.13 \pm 1.09$ & $87.0 \pm 0.9$ \\
$\mathrm{Cr}_{3} \mathrm{C}_{2}-25 \% \mathrm{NiCr}$ & $433 \pm 9$ & $6.86 \pm 1.07$ & $84.0 \pm 0.5$ \\
$(\mathrm{Ti}, \mathrm{Mo})(\mathrm{C}, \mathrm{N})-37 \% \mathrm{NiCo}$ & $430 \pm 7$ & $7.87 \pm 0.86$ & $91.5 \pm 1.5$ \\
\hline
\end{tabular}
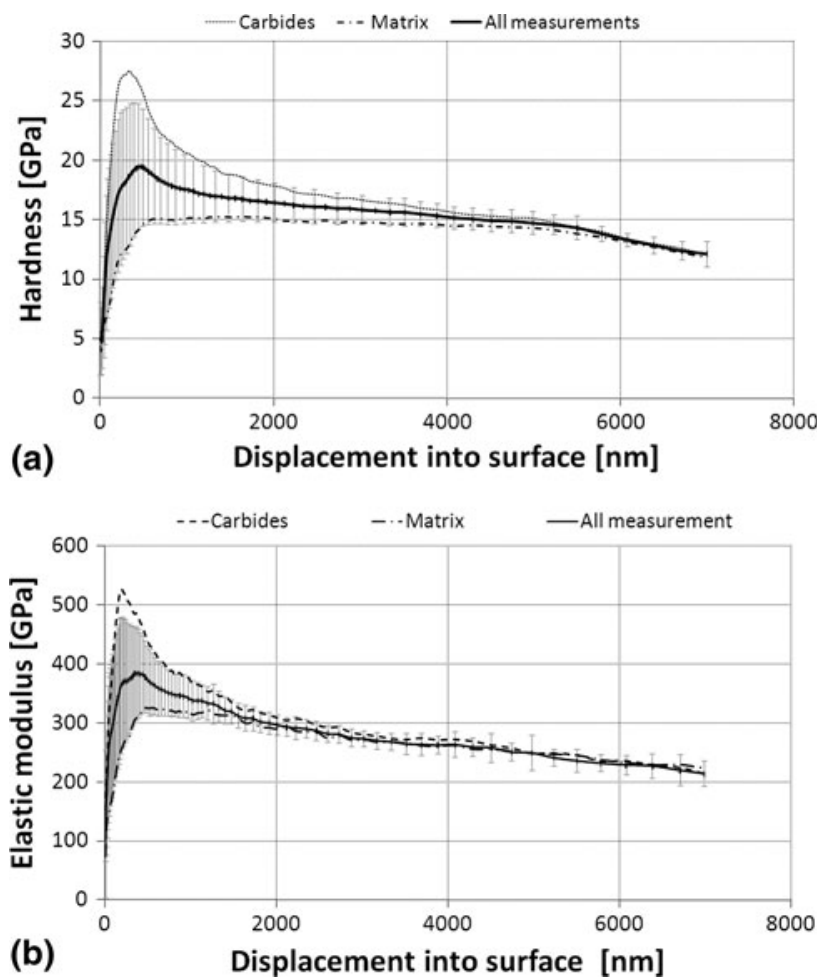

Fig. 2 The hardness (a) and Young elastic modulus (b) dependence on displacement into surface of WC-17\% Co coating

considered to represent carbides, dashed line stands for an average of the measurements considered to represent the matrix, and the unbroken line includes all the 50 measurements made in each coating.

The analysis of the CSM dependences indicates that for each coating the maximum values of $H_{\mathrm{IT}}$ and $E_{\mathrm{IT}}$ could be measured at various depths.

In the case of the WC- $17 \%$ Co coating, the maximum measured for carbide hardness, $27.5 \mathrm{GPa}$, is reached at the depth of $342 \mathrm{~nm}$, whereas the maximum measured for Young's modulus of carbide, $525 \mathrm{GPa}$, is reached at the depth of $185 \mathrm{~nm}$. The foregoing lower values, measured at smaller depths, should not be taken into account. They are influenced by the stiffness of the measuring system, imperfections of the indenter tip, and, probably, by the elastic effect of the surrounding phase as well.

The true values of properties of the matrix are difficult to determine. Owing to the low volume of the matrix material, the carbides influence the measured values from the very beginning. The influences of stiffness of the
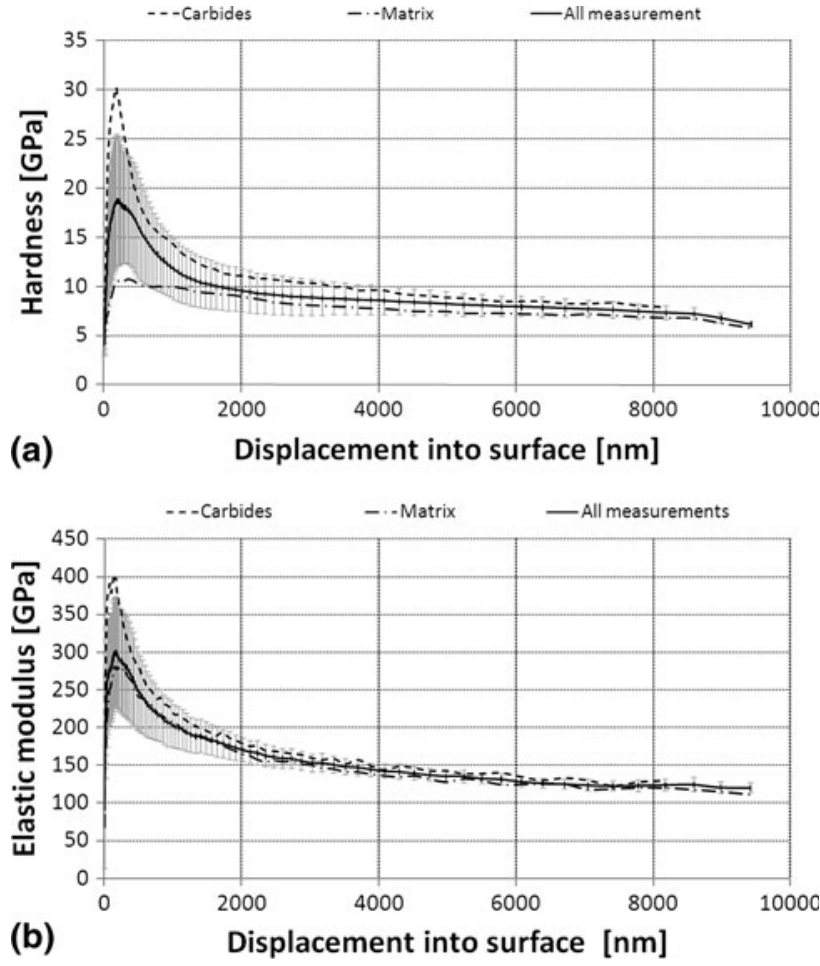

Fig. 3 The hardness (a) and Young elastic modulus (b) dependence on displacement into surface of $\mathrm{Cr}_{3} \mathrm{C}_{2}-25 \% \mathrm{NiCr}$ coating
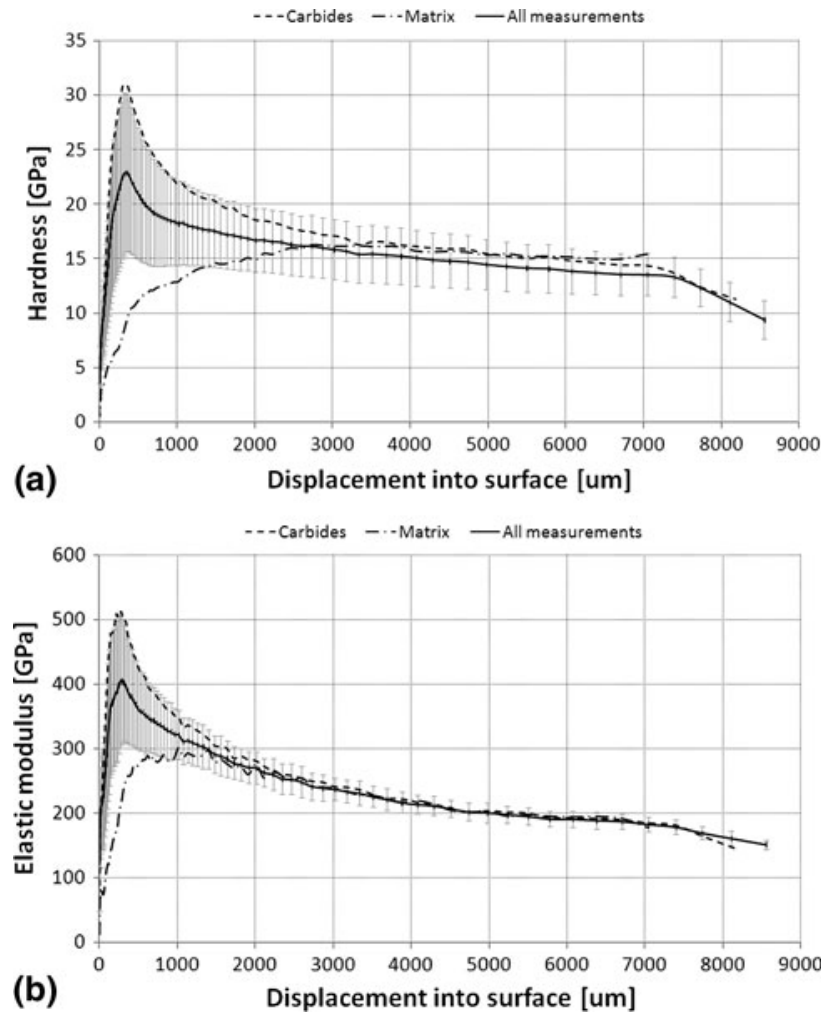

Fig. 4 The hardness (a) and Young elastic modulus (b) dependence on displacement into surface of $(\mathrm{Ti}, \mathrm{Mo})(\mathrm{C}, \mathrm{N})$ $37 \% \mathrm{NiCo}$ coating 


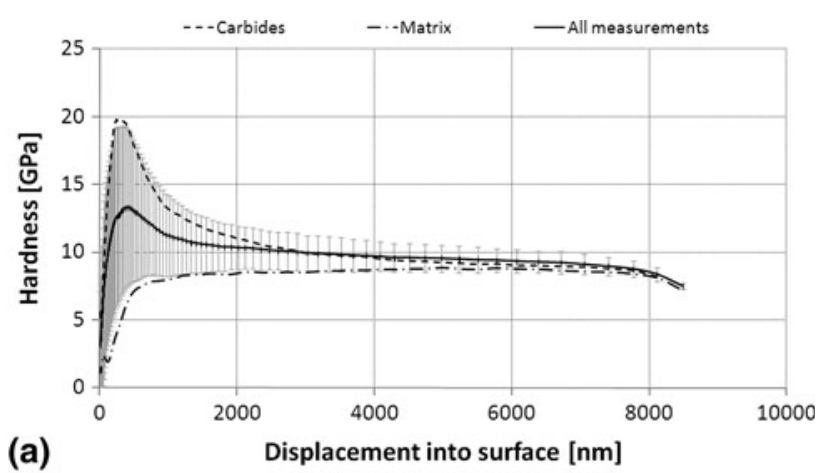

(a)

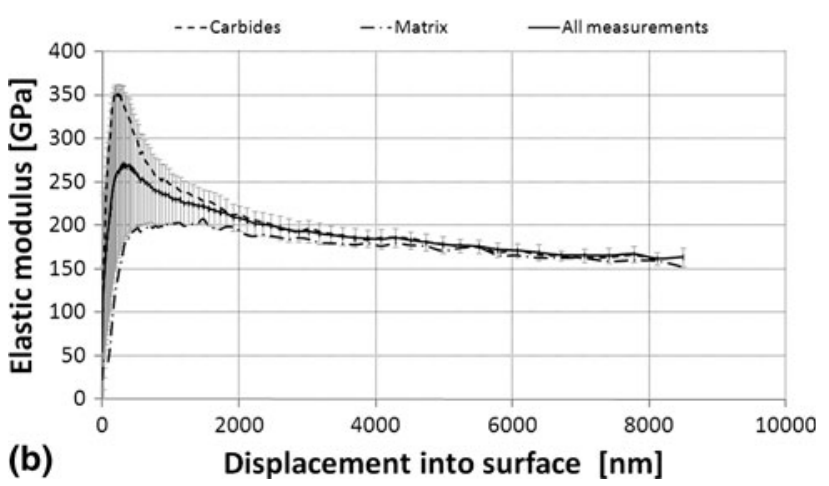

Fig. 5 The hardness (a) and Young elastic modulus (b) dependence on displacement into surface of WC-12\% Co coating
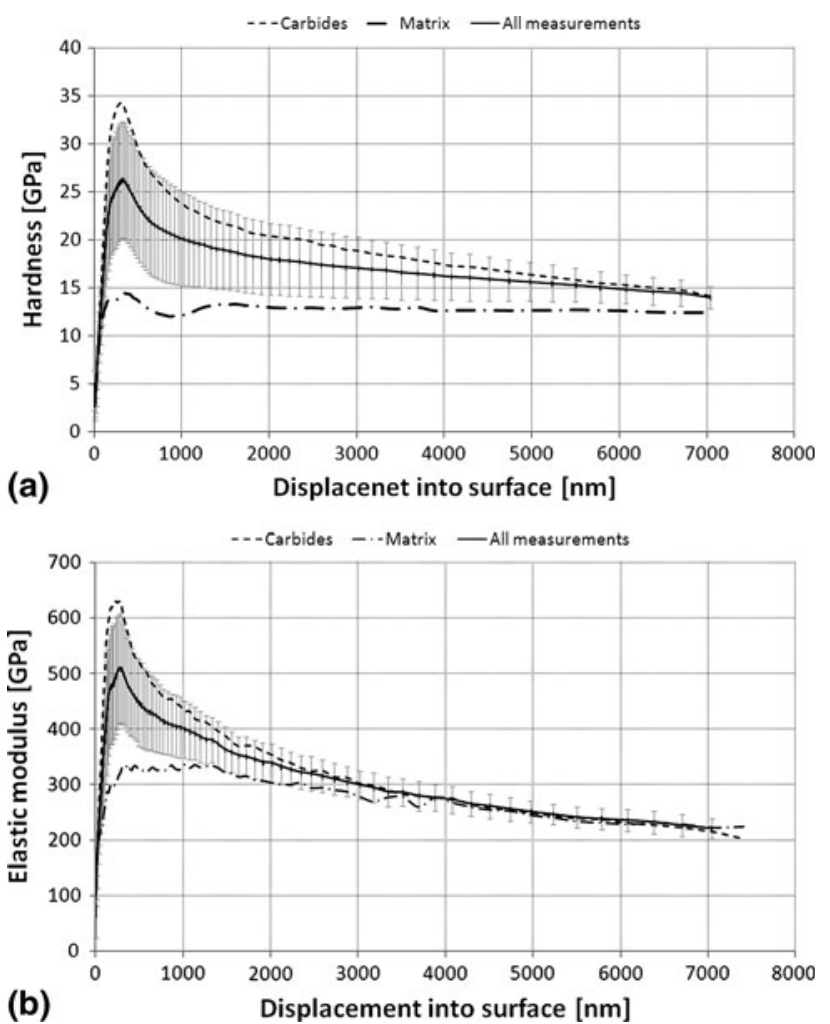

Fig. 6 The hardness (a) and Young elastic modulus (b) dependence on displacement into surface of $\mathrm{WC}-20 \% \mathrm{CrC}-7 \% \mathrm{Ni}$ coating system and indenter tip imperfections are followed by the influence of carbides in the coating's structure. The maximum hardness value of Co matrix is reached at the depth of $1399 \mathrm{~nm}$. At this depth of indentation, more than one carbide is included in the measured material volume, considering the coating's microstructure.

Similar behavior can be observed in all the measured coatings. The maximum hardness of hard particles is reached at greater depths of indentation when compared to the maximal Young's modulus, but the differences are not as large.

The maximum values measured $H_{\mathrm{IT}}$ and $E_{\mathrm{IT}}$ values for hard particles and matrix and corresponding displacements into surface $h_{\mathrm{H}}$ and $h_{\mathrm{E}}$ obtained from CSM measurements are summarized in Table 3.

The measured values are in good agreement with data reported in the literature. Hardness and Young's modulus of WC are reported to be 23 and $580 \mathrm{GPa}$ respectively; and 27 and $360 \mathrm{GPa}$ respectively for $\mathrm{Cr}_{3} \mathrm{C}_{2}$ (Ref 37). Gee in his study of coatings hardness (Ref 17) measured $H_{\mathrm{IT}}$ of WC particles in the range between $30-50 \mathrm{GPa}$, and $\mathrm{Co}$ matrix in the range of 20-40 GPa. However, he considered the values as too large.

The measured $H_{\mathrm{IT}}$ and $E_{\mathrm{IT}}$ values of hard particles, matrix, and the high amount of indentations provided information about the carbide-matrix mixture, which was confirmed also by the grid indentation. It was realized on the $\mathrm{WC}-17 \% \mathrm{Co}, \mathrm{Cr}_{3} \mathrm{C}_{2}-25 \% \mathrm{NiCr}$, and $(\mathrm{Ti}, \mathrm{Mo})(\mathrm{C}, \mathrm{N})-$ $39 \% \mathrm{NiCo}$ coatings. The results of the experiment will be published in the near future.

With increasing load, the displacement of the indenter tip into surface increases, and, consequently, the measured volume of material grows as well. Measurement of the properties of the hard particle begins to be influenced by the surrounding soft matrix and vice versa: measurement of matrix properties is influenced by close hard particles. Curves for displacement into surface for both carbides and matrix $H_{\mathrm{IT}}\left(E_{\mathrm{IT}}\right)$ lie close to each other. Beyond the transition indentation depth, they overlap.

In thermally sprayed hardmetals, the mutual influence between hard particles and matrix exists and properties within a single splat can be measured until the affected volume of material reaches the splat boundary. With further increase in load, additional microstructural features, such as splat boundaries, pores, oxides, and other coating inhomogenities are progressively included in the measured volume of the coating's material. The measurement then yields the properties of the coating as a whole.

The transition indentation depth $\left(h_{\mathrm{C}}\right)$ represents the displacement into surface, enabling the measurement of properties of the entire coating. It varies for each coating, depending on splat proportions, i.e., powder size distribution and spraying conditions. However, for finding $H_{\text {IT }}$ and $E_{\mathrm{IT}}$ values for a coating, $2 \mu \mathrm{m}$ can be considered as the general transition indentation depth for HVOFsprayed coatings evaluated in this study (see Fig. 2-6). The transition depths, as well as $H_{\mathrm{IT}}$ and $E_{\mathrm{IT}}$ values calculated as average values from measurement in the range of $2 \mu \mathrm{m}$-maximum indentation depth, are mentioned in Table 3. 
Table $3 H_{\mathrm{IT}}$ and $E_{\mathrm{IT}}$ values for carbides, matrixes and coatings

\begin{tabular}{lccc}
\hline Coating & $\boldsymbol{H}, \mathbf{G P a}$ & $\boldsymbol{h}_{\mathbf{H}}, \mathbf{n m}$ & $\boldsymbol{E}, \mathbf{G P a}$ \\
\hline Carbide & & & $\boldsymbol{h}_{\mathbf{E}}, \mathbf{n m}$ \\
WC-12\%Co & $34.3 \pm 2.9$ & 322 & $630 \pm 45$ \\
WC-17\%Co & $27.5 \pm 1.5$ & 342 & $525 \pm 50$ \\
WC-20\%CrC-7\%Ni & $30.8 \pm 1.0$ & 364 & $508 \pm 34$ \\
CrC-25\%NiCr & $30.2 \pm 0.8$ & 185 & $398 \pm 7$ \\
(Ti,Mo)(C,N)-37\%NiCo & $19.8 \pm 3.4$ & 247 & $353 \pm 56$ \\
Matrix & $14.4 \pm 0.6$ & 343 & $344 \pm 9$ \\
WC-12\%Co & $15.2 \pm 1.6$ & 1399 & $325 \pm 29$ \\
WC-17\%Co & $14.2 \pm 0.7$ & 3336 & $301 \pm 4$ \\
WC-20\%CrC-7\%Ni & $10.7 \pm 1.2$ & 346 & $280 \pm 47$ \\
CrC-25\%NiCr & $8.8 \pm 0.6$ & 5777 & $207 \pm 13$ \\
(Ti,Mo)(C,N)-37\%NiCo & & 465 \\
\hline
\end{tabular}

\begin{tabular}{lccr} 
& & \multicolumn{2}{c}{ Coating } \\
\cline { 2 - 4 } Coating & $\boldsymbol{H , ~ G P a}$ & $\boldsymbol{E}, \mathbf{G P a}$ & \\
\hline WC-12\%Co & $16.3 \pm 1.1$ & $278 \pm 36$ & 1450 \\
WC-17\%Co & $15.1 \pm 1.2$ & $259 \pm 26$ & 1500 \\
WC-20\%CrC-7\%Ni & $14.6 \pm 1.6$ & $214 \pm 31$ & 2000 \\
CrC-25\%NiCr & $8.3 \pm 0.8$ & $142 \pm 15$ & 1450 \\
(Ti,Mo)(C,N)-37\%NiCo & $9.5 \pm 0.6$ & $183 \pm 13$ & 1600 \\
\hline
\end{tabular}
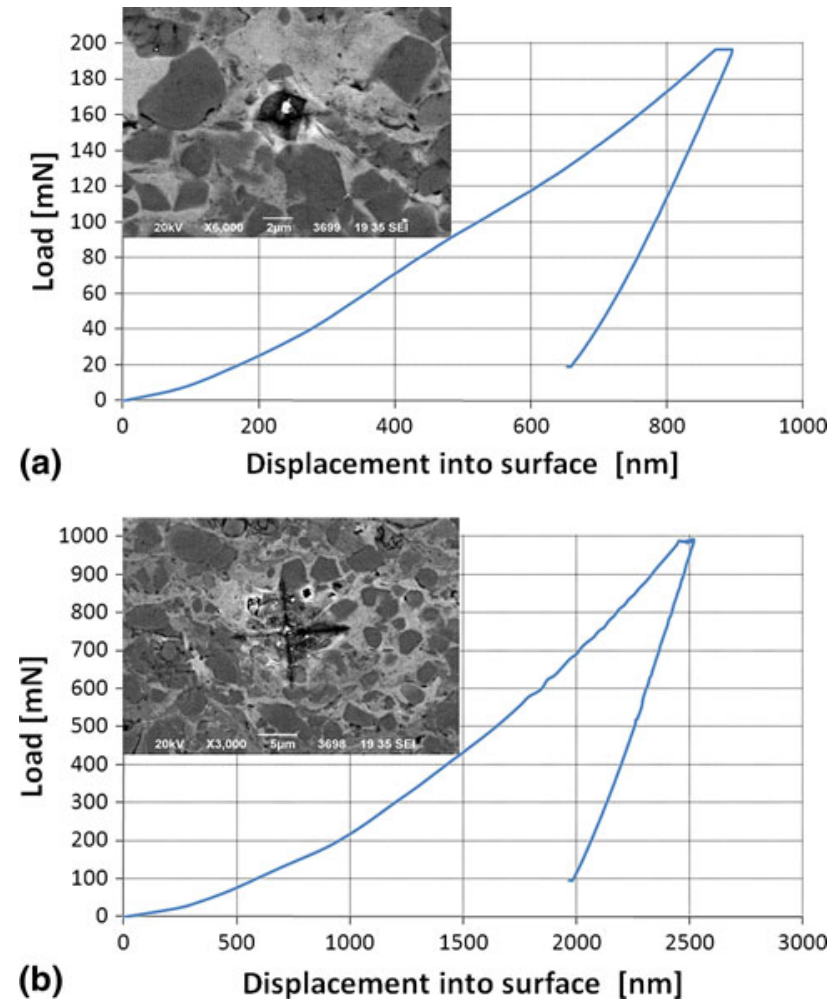

Fig. 7 The load-displacement curves of $\mathrm{Cr}_{3} \mathrm{C}_{2}-25 \% \mathrm{NiCr}$ with the SEM of indents made at (a) $200 \mathrm{mN}$ and (b) $1 \mathrm{~N}$

To confirm the transition depths, measurement at defined loads was carried out, and the size of indents was analyzed using SEM. In Fig. 7, the indents and corresponding load-displacement curves obtained for $200 \mathrm{mN}$ and $1 \mathrm{~N}$ in the $\mathrm{Cr}_{3} \mathrm{C}_{2}-25 \% \mathrm{NiCr}$ coating are shown.

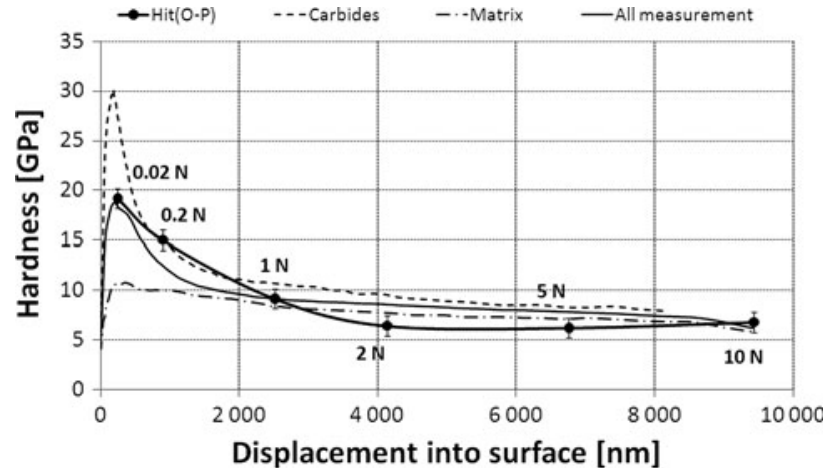

Fig. 8 Comparison between CSM measurements and defined load measurements for $\mathrm{Cr}_{3} \mathrm{C}_{2}-25 \% \mathrm{NiCr}$ coating

The indent made at $0.2 \mathrm{~N}$ (Fig. 7a) reached the depth of $900 \mathrm{~nm}$. As the scanning micrograph shows, it is small enough to represent the properties of a single splat, but too large to only include the volume of a single hard particle. It includes not only a contribution from the measured carbide, but also the contribution from the surrounding matrix.

For lower loads, the indents were too small to be found in the SEM.

The indent made at $1 \mathrm{~N}$ (Fig. 7b) reached the depth of indentation $2.5 \mu \mathrm{m}$. SEM observation confirmed that the measured volume of material includes more than one splat and the values of $H_{\mathrm{IT}}$ and $E_{\mathrm{IT}}$, determined at the load $1 \mathrm{~N}$ can be considered as the coating's properties.

In Fig. 8, comparison of results of CSM measurements and measurements at defined loads is shown. The $H_{\mathrm{IT}}$ values, obtained at defined load, are in agreement with the average CSM curve obtained from all the 50 CSM measurements that were realized. 
Among the 50 CSM measurements, only a few were identified as results characterizing hard particles only. Even fewer were classified as measurement of the matrix. Most $H_{\mathrm{IT}} / E_{\mathrm{IT}}$-displacements into surface curves comprise contributions from hard particles and matrix. However, hardness and Young's modulus of hard particles are relatively high when compared to these values of the matrix. Moreover, the hard particle volume fraction in the structure is much higher. Their influence on the average $H_{\mathrm{IT}}\left(E_{\mathrm{IT}}\right)$-displacement into surface curve is dominant, and the average curve is closer to the $H_{\mathrm{IT}}\left(E_{\mathrm{IT}}\right)$-displacement into surface curve of hard particles.

The dependence of $H_{\mathrm{IT}}$ measured at a defined load on the depth of indentation indicates the indentation size effect observed in hardness measurement of many materials. The so-called indentation size effect (ISE) has been intensively studied in the literature. The identified responsible causes and mechanism differs in respect of dependences on tested material: study hardening, roughness, pilling-up, sinking-in, shape of the indentor, surface energy, varying composition and crystal anisotropy, presence of oxide layers, chemical contamination of the surface, etc. They are extensively discussed in the overviews (Ref 11, 12, 16). Two different ISE behaviors were observed in terms of dependence indentation range: microhardness and nano-indentation hardness. While for the interpretation of microhardness data, the Nix and Gao's concept of geometrically necessary dislocations (GNDs) (Ref 15) are commonly accepted, the nano-indentation hardness data do not follow the same mathematical representation. Chicot in his study (Ref 16) demonstrated that the difference between the nano- and micro-indentation comes from the dislocation spacing under the indent and is linked to the maximum allowable GND density and associated effect on the size of the plastic zone. He also pointed to the fact that the transition depth between nano-indentation hardness and microhardness referred by some other authors (Ref 13) was in the range of 100-300 $\mu \mathrm{m}$.

After contrasting with the results of CSM measurements, the decrease in the values of the $H_{\mathrm{IT}}$ and $E_{\mathrm{IT}}$ with increasing load/depth in the case of thermally sprayed hardmetal coatings should be attributed to different causes.

Based on the observations mentioned above, for the case of thermally sprayed coatings, the seeming similarity in behavior has two different origins. In the range of intersplat properties, the shape of the average $H_{\mathrm{IT}}\left(E_{\mathrm{IT}}\right)$-displacement into surface curve for hardmetal results from the contribution of two structural phases. The predominant one involves high hardness and Young's modulus, whereas the minor one includes lower hardness and Young's modulus. After crossing the splat boundaries, $H_{\mathrm{IT}}$ and $E_{\mathrm{IT}}$ tend to decrease with a very moderate slope. The mild decreases in hardness and Young's modulus values with increasing load are caused by the growing number of coating's defects and splat boundaries that are included in the affected area.

The transition indentation depth $\left(h_{\mathrm{C}}\right)$ between the inters-splat properties and the properties of entire coating referred in this study has not the same meaning as the transition depth between to the nano- and micro-hardness data referred in Ref 16 . It is reached in the depths range $1500-2000 \mathrm{~nm}$, and is connected with the coatings microstructure, namely, with the size of the splats.

Average values of hardness and Young's modulus obtained in this study are in agreement with the values measured by a different type of hardness testing methodology (Ref 26, 27). The authors of both these studies reported the values of $H_{\mathrm{IT}}$ and $E_{\mathrm{IT}}$ of $\mathrm{HVOF}$-sprayed WC-based coating in the range of in-splat properties, thus showing the dependence on the indentation load.

A study similar to the one reported here was published by Santana et al. (Ref 24) for WC-based HVOF-sprayed coatings. Measured values of hardness and Young's modulus are in a very close correlation to the values measured in this study. The same observations concerning the transition depth of $2 \mu \mathrm{m}$, beyond which the hardness remains approximately constant, were made. On the other hand, Santana et al (Ref 24) concentrated primarily on the anisotropy of the thermal spray coatings without focusing on interpretation of measured data in the range of in-splat properties.

From the application point of view, the accurate values for single phases in the coatings are not so important to be measured; both can be easily found in the literature. The point of interest is that the properties of coating on the scale corresponding with wear processes. The nature of the indentation process is very similar to the processes that take place in certain types of wear, such as abrasive or erosive wear ( Ref 25$)$. In those cases, the abrasive media usually damage the coating's surface by scratching or rubbing. Wear resistance of the coating material is then determined by local elastic-plastic properties of the coating.

While microhardness is one of the routinely measured and reported properties, representing the local resistance of the material against indentation, the value of Young's modulus of coatings is rarely reported because of demanding experimental methods of measurement. The generally accepted statement that the Young's modulus of thermally sprayed coating reaches $20-30 \%$ of the value for bulk materials (Ref 38-40) is valid for the macro-scale Young's modulus, where the overall coating's porosity, microcracks in the coating, and splat boundaries play their respective roles.

The choice of the methodology for measuring the Young's modulus determines the volume of the tested material and, consequently, the obtained value of $E$ (Ref 41). The local Young's modulus is influenced by a lower amount of coating's inhomogenities, and its ratio to $E$ of the bulk material is higher.

Based on the measured data, the ratio of $E_{\mathrm{IT}}$ to $E$ bulk (560 GPa for $\mathrm{WC}-17 \% \mathrm{Co}, 580 \mathrm{GPa}$ for $\mathrm{WC}-12 \% \mathrm{Co}$ and $320 \mathrm{GPa}$ for $\mathrm{Cr}_{3} \mathrm{C}_{2}-25 \% \mathrm{NiCr}$; Ref 25,42$)$, reached more than $45 \%$.

The difference between the WC-based coatings with various amounts of Co matrix matched the expected value. The influence of the Co content on microhardness, Young's modulus and fracture toughness was also evaluated by Chivavibul et al. (Ref 43) who confirmed the

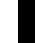




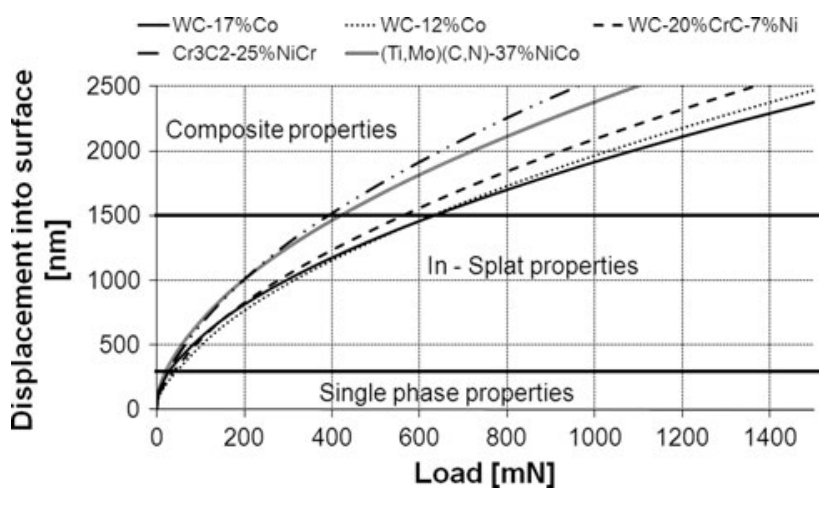

Fig. 9 The transition depths of indentation and coatings loaddisplacement curves

tendency of $H$ and $E$ to decrease with increasing proportion of the Co matrix.

\section{Conclusion}

Results of this study show that instrument-based measurement of hardness and Young's modulus of thermally sprayed hardmetal coatings at low loads captures the properties of hard particles, of not only the soft matrix but also the combination of both. With sufficient amount of measured data, one can distinguish between these tree types of results.

With increasing load, single phase measurement leads to the measurement of the in-splat properties. The influence of the indent's neighborhood grows stronger, and the slope of the $H_{\mathrm{IT}}\left(E_{\mathrm{IT}}\right)$-displacement into surface curve changes rapidly. The values of $H_{\mathrm{IT}}$ and $E_{\mathrm{IT}}$ combine the characteristics of hard particles and soft matrix.

With further increase in load, splat boundaries are included in the measured volume. The values of $H_{\mathrm{IT}}$ and $E_{\mathrm{IT}}$ obtained at loads exceeding the load corresponding to the transition indentation depth of $2 \mu \mathrm{m}$ (about $1 \mathrm{~N}$ for coatings measured in this study) represent the properties of the entire coating. Values measured within this load scale include information about the coating's composite properties including-several splat boundaries, pores, oxides, or microcracks. Indentation depths for transition between the region of single-phase properties, in-splat properties, and coating's composite properties for coatings evaluated here are visualized in Fig. 9.

The above described mechanism of the predominant influence of the hard phase in the measurement of in-splat properties, followed by the increasing influence of splat boundaries, pores, oxides, microcracks, etc. in the coating, can explain the origin of the so-called ISE effect in the case of thermally sprayed hardmetal coatings.

The values of $H_{\mathrm{IT}}$ and $E_{\mathrm{IT}}$, determined as average of values and measured in the range of $2 \mu \mathrm{m}$-maximum depth of indentation at $10 \mathrm{~N}$ by continuous stiffness indentation method, represent the mechanical properties of the coating at micro-scale, which can be used for further characterization of the coating, for example, in the indentation fracture toughness equations $(\operatorname{Ref} 7,44,45)$ or for wear prediction equations (Ref 46-49).

\section{Acknowledgment}

The authors acknowledge with thanks the support received under the project No. FR-TI1/123 from the Czech Ministry of Education, Youth and Sports for the submission of this article.

\section{References}

1. L.C. Erickson, H.M. Hawthorne, and T. Troczynski, Correlations between Microstructural Parameters, Micromechanical Properties and Wear Resistance of Plasma Sprayed Ceramic Coatings, Wear, 2001, 250, p 569-575

2. K. Holmberg and A. Matthews, Coatings Tribology, Elsevier, Amsterdam, 1998

3. J. Li, J. Zang, and C. Ding, Mechanical and Tribological Properties of Plasma-Sprayed $\mathrm{Cr}_{3} \mathrm{C}_{2}-\mathrm{NiCr}$, WC-Co, and $\mathrm{Cr}_{2} \mathrm{O}_{3}$ Coatings, J. Therm. Spray Technol., 1998, 7, p 242-246

4. A.A. Syed, G. Antou, and A. Denoirjean, High Temperature Mechanical Properties of Plasma Sprayed Thin YSZ Deposits, Thermal Spray 2007: Global Coating Solutions, B.R. Marple, M.M. Hyland, Y.-C. Lau, C.-J. Li, R.S. Lima, and G. Montavon, Ed., Marz 14-16, 2007 (Beijing, China), ASM International, 2007, p 971-976

5. T. Varis, E. Rajamaki, and K. Korpiola, Mechanical Properties of Thermal Spray Coatings, Thermal Spray 2001: New Surfaces for a New Millennium, C.C. Berndt, K.A. Khor, and E.F. Lugscheider, Ed., May 28-30, 2001 (Singapore), ASM International, 2001, p 993-997

6. S. Bouaricha, J.-G. Legoux, and P. Marcoux, Bending Behavior of HVOF Produced WC-17Co Coating: Investigated by Acoustic Emission, J. Therm. Spray Technol., 2004, 13, p 405-414

7. C.B. Ponton and R.D. Rawlings, Vickers Indentation Fracture Toughness Test Part 1, Mater. Sci. Technol., 1989, 5, p 865-872

8. W.W. Gerberich, N.I. Tymiak, J.C. Grunlan, M.F. Horstemeyer, and M.I. Baskes, Interpretations of Indentation Size Effects, J. Appl. Mech., 2002, 69, p 433-442

9. P.M. Sargent, Indentation Size Effect and Strain-Hardening, J. Mater. Sci. Lett., 1989, 8, p 1139-1140

10. G.M. Pharr, E.G. Herbert, and Y. Gao, The Indentation Size Effect: A Critical Examination of Experimental Observations and Mechanistic Interpretation, Annu. Rev. Mater. Res., 2010, 40, p 242-271

11. A.A. Elmustafa and D.S. Stone, Nanoindentation and the Indentation Size Effect: Kinetics of Deformation and Strain Gradient Plasticity, J. Mech. Phys. Solids, 2003, 51, p 357-381

12. Y.T. Cheng and C.M. Cheng, Scaling, Dimensional Analysis, and Indentation Measurements, Mater. Sci. Eng. R, 2004, 44, p 91-149

13. Y. Huang, F. Zang, K.C. Hwang, W.D. Nix, G.M. Pharr, and G. Feng, A Model of Size Effects in Nano-Indentation, J. Mech. Phys. Solids, 2006, 54, p 1668-1686

14. D. Tabor, The Hardness of Metals, Oxford University Press, Oxford, 2000

15. W.D. Nix and H. Gao, Indentation Size Effect in Crystalline Materials: A Low for Strain Gradient Plasticity, J. Mech. Phys. Solids, 1998, 46, p 41-425

16. D. Chicot, Hardness Length-Scale Factor to Model Nano- and Micro-Indentation Size Effects, Mater. Sci. Eng. A, 2009, 499, p 454461

17. M.G. Gee, B. Roebuck, P. Lindahl, and H.-O. Andren, Constituent Phase Nanoindentation of $\mathrm{WC} / \mathrm{Co}$ and $\mathrm{Ti}(\mathrm{C}, \mathrm{N})$ Hard Metals, Mater. Sci. Eng. A, 1996, 209, p 128-136

18. J.M. Guilemany, M. Torrell, S. Dosta, and J.R. Miguel, Corrosion Protection of Municipal Solid Waste Incinerator Superheaters by HVOF Thermal Spray Coatings, Thermal Spray 2008: Crossing 
Borders, B.R. Marple, M.M. Hyland, Z.-C. Lau, C.-J. Li, R.S. Lima, and G. Montavon, Ed., June 2-4, 2008 (Maastricht, The Netherlands), ASM International, 2008, p 305-308

19. X.Q. Ma, D.W. Gandy, and G.J. Frederick, Revealing Mechanical Properties of a Suspension Plasma Sprayed Coating with Nanoindentation, Surf. Coat. Technol., 2009, 203, p 2995-2999

20. A. Stravato, R. Knight, V. Mochalin, and S.C. Picardi, HVOFSprayed Nylon-11 + Nanodiamond Composite Coatings: Production \& Characterization, J. Therm. Spray Technol., 2008, 17, p 812-817

21. A. Hall, P. Yang, L. Brewer, T. Buchheit, and T. Roemer, Preparation and Mechanical Properties of Cold Sprayed Nanocrystalline Aluminum, Thermal Spray 2008: Crossing Borders, B.R. Marple, M.M. Hyland, Z.-C. Lau, C.-J. Li, R.S. Lima, and G. Montavon, Ed., June 2-4, 2008 (Maastricht, The Netherlands), ASM International, 2008, p 604-608

22. G. Bolelli, J. Rauch, V. Cannillo, A. Killinger, L. Lusvarghi, and R. Gadow, Microstructural and Tribological Investigation of High-Velocity Suspension Flame Sprayed (HVSFS) $\mathrm{Al}_{2} \mathrm{O}_{3}$ Coatings, J. Therm. Spray Technol., 2009, 18, p 35-49

23. A. Abdel-Samad, E. Lugscheider, K. Bobzin, and K. Maes, The Influence of Post Heat Treatment Processes on Thermal Fatigue Resistance of Thermally Sprayed Coatings, Thermal Spray 2004: Advances in Technology and Applications, B.R. Marple and C. Moreau, Ed., May 10-12, 2004 (Osaka, Japan), ASM International, 2004, p 903-907

24. Y.Y. Santana, J.G. La Barbera-Sosa, J. Caro, E.S. Puchi-Carbera, and M.H. Staia, Mechanical Properties and Microstructure of WC-10Co-4Cr and WC-12Co Thermal Spray Coatings Deposited by HVOF, Surf. Eng., 2008, 24, p 374-382

25. I. Hussainova, J. Kubarsepp, and J. Pirso, Mechanical Properties and Features of Erosion Of Cermets, Wear, 2001, 250, p 818-825

26. J. Nohava, Ed., Characterization of Thermal Spray Coatings by Instrumented Indentation and Scratch Testing: Part I, Application Bulletin No. 28, CSM Instrumets, 2009

27. O. Culha, M. Toparli, E. Celik, T. Aksoy, and H.S. Soykan, Indentation Size Effect on Mechanical Properties of HVOF Sprayed WC Based Cermet Coatings for a Roller Cylinder, Surf. Coat. Technol., 2009, 203, p 2052-2057

28. C.V. Cojocaru, Y. Wang, C. Moreau, R.S. Lima, J. MesquitaGuimarães, E. Garcia, P. Miranzo, and M.I. Osendi, Mechanical Behavior of Air Plasma-Sprayed YSZ Functionally Graded Mullite Coatings Investigated via Instrumented Indentation, $J$. Therm. Spray Technol., 2011, 20, p 100-107

29. W. Tillmann, B. Klusemann, J. Nebel, and B. Svendsen, Analysis of the Mechanical Properties of an Arc-Sprayed WC-FeCSiMn Coating: Nanoindentation and Simulation, J. Therm. Spray Technol., 2011, 20, p 328-335

30. J.G. Barbera-Sosa, Y.Y. Santana, M.H. Staia, D. Chicot, J. Lasage, J. Caro, G. Mesmacque, and E.S. Puchi-Cabrera, Microstructural and Mechanical Characterization of Ni-base Thermal Spray Coatings Deposited by HVOF, Surf. Coat. Technol., 2008, 202, p 4552-4559

31. L.-M. Berger, W. Hermel, P. Vuoristo, and W. Lengauer, Structure, Properties and Potentials of WC-Co, $\mathrm{Cr}_{3} \mathrm{C}_{2}-\mathrm{NiCr}$ and TiCNi Based Hardmetal-like Coatings, Thermal Spray: Practical Solutions for Engineering Problems, C.C. Berndt, Ed., October 711, 1996 (Cincinnati, OH), ASM International, 1996, p 89-96

32. L.-M. Berger, S. Saaro, C. Jordan, T. Neumann, M. Kašparová, and M. Zahálka, HVOF-Sprayed WC-(W,Cr) ${ }_{2} \mathrm{C}-\mathrm{Ni}$ Coatings and their Properties, Thermal Spray 2008: Crossing Borders, B.R. Marple, M.M. Hyland, Z.-C. Lau, C.-J. Li, R.S. Lima, and G. Montavon, Ed., June 2-4, 2008 (Maastricht, The Netherlands), ASM International, 2008, p 217-222
33. L.-M. Berger, S. Saaro, T. Neumann, M. Kašparová, and M. Zahálka, Influence of Feedstock Powder Characteristics and Spray Processes on Microstructure and Properties of WC-(W, Cr)2C-Ni Hardmetal Coatings, Coat. Surf. Technol., 2010, 205, p 1080-1087

34. L.-M. Berger, S. Zimmermann, H. Keller, G. Schwier, S. Thiele, M. Nebelung, and R. Enžl, Microstructure and Properties of HVOF-Sprayed TiC-Based Coatings, Thermal Spray 2003: Advancing the Science \& Applying the Technology, B.R. Marple, C. Moreau, Ed., May 5-8, 2003 (Orlando, FL), ASM International, 2003, p 793-799

35. L.-M. Berger, S. Thiele, P. Vuoristo, and T. Mäntylä, Titanium Carbide-Based Powders and Coatings-Composition, Processability and Properties, International Thermal Spray Conference 2002, E. Lugscheider and C.C. Berndt, Ed., March 4-6, 2002 (Essen, Germany), DVS Germany, 2002, p 727-723

36. W.C. Oliver and G.M. Pharr, An Improved Technique for Determining Hardness and Elastic Modulus Using Load and Displacement Sensing Indentation Experiments, J. Mater. Res., 1992, 7(6), p 1564-1583

37. W. Lengauer, Transition Metal Carbides, Nitrides and Carbonitrides, Handbook of Ceramic Hard Materials, Vol 1, WileyVCH, Weinheim, 2000, p 202-252

38. R. McPherson, A Review of Microstructure and Properties of Plasma Sprayed Ceramic Coatings, Surf. Coat. Technol., 1989, 3940, p 173-181

39. R. McPherson, A Model for the Thermal Conductivity of PlasmaSprayed Ceramic Coatings, Thin Solid Film, 1984, 112, p 89-95

40. R.S. Lima, A. Kucuk, and C.C. Berndt, Evaluation of Microhardness and Elastic Modulus of Thermally Sprayed Nanostructured Zirconia Coatings, Surf. Coat. Technol., 2001, 135, p 166-172

41. N. Margadant, J. Neuenschwander, S. Stauss, H. Kaps, A. Kulkarni, J. Matejicek, and G. Rössler, Impact of Probing Volume from Different Mechanical Measurement Methods on Elastic Properties of Thermally Sprayed Ni-Based Coatings on a Mesoscopic Scale, Surf. Coat. Technol., 2000, 200, p 2805-2820

42. H. Kolaska and W. Weith, Hardmetalls as Material for Components in Industrial Applications, Part 1, Metall., 1995, 49(20), p 104-111 (in German)

43. P. Chivavibul, M. Watanabe, S. Kuroda, and K. Shinoda, Effect of Carbide Size and Co Content on the Microstructure and Mechanical Properties of HVOF-Sprayed WC-Co Coatings, Surf. Coat. Technol., 2007, 202, p 509-521

44. D. Chicot, G. Duarte, A. Tricoteaux, B. Jorgowski, A. Leriche, and J. Lasage, Vickers Indentation Fracture (VIF) Modeling to Analyze Multi-Cracking Toughness of Titania, Alumina and Zirconia Plasma Sprayed Coatings, Mater. Sci. Eng. A, 2009, 527, p 65-76

45. C.T. Rios, A.A. Coelho, M.C. Batista, and R. Caram, ISE and Fracture Toughness Evaluation by Vickers Hardness Testing of an Al3Nb-Nb2Al-AlNbNi in Situ Composite, J. Alloys Compd., 2009, 472, p 65-70

46. S.F. Wayne and S. Sampath, Structure/Property Relationships in Sintered and Thermally Sprayed WC-Co, J. Therm. Spray Technol., 1994, 1, p 307-315

47. S.M. Hsu and M. Shen, Wear Predictions of Ceramics, Wear, 2004, 256, p 867-878

48. H.C. Meng and K.C. Ludema, Wear Models and Predictive Equations: Their Form and Content, Wear, 1995, 181, p 443457

49. G. Bolelli, V. Cannillo, L. Lusvarghi, and S. Riccò, Mechanical and Tribologival Properties of Electrolytic Hard Chrome and HVOFSprayed Coatings, Surf. Coat. Technol., 2006, 200, p 2995-3009 